\title{
Chapter
}

\section{The Revolutionary Media Education Decade: From the UNESCO to the ALFAMED Curriculum for Teacher Training}

\author{
Paula Renés-Arellano, Ignacio Aguaded \\ and Maria Jose Hernández-Serrano
}

\begin{abstract}
Nations across the globe are immersed in a technological revolution-intensified by the need to respond to COVID-19 issues. In order to be critical and responsible citizens in the current media ecosystem, it is important that students acquire and develop certain skills when consuming and producing information for and when communicating through the media. This is a major challenge that educational systems worldwide have to face. Hence, new curricula in media education to guide future teachers towards the successful acquisition of new media skills have been proposed. The aims of this work are to conduct a theoretical approach to this worldwide technological and media evolution in the past decade, to make an indepth comparison between the Curriculum for teachers on media and information literacy published by the UNESCO (2011) and the publication of the new AlfaMed Curriculum for the training of teachers in media education (2021). This framework starts by providing an extensive analysis of the key elements of both curricula and of their corresponding modules, establishing, thus, a constructive comparison while updating them, according to the needs, changes, and realities that have taken place regarding digital literacy in the past decade. Finally, the chapter concludes with the detailing of the challenges and with proposals for teacher training in media and information literacy.
\end{abstract}

Keywords: Media and Information Literacy, EduCommunication, digital competences, curriculum innovation, teacher training

\section{Introduction}

The world, particularly developed nations, is undergoing a process of technological changes that has been especially influenced by the COVID-19 pandemic-it has changed how we interact with each other and our understanding of society. This upcoming decade will be of utmost importance in regard to educating and empowering people so they will be able to face these new digital media challenges.

In its latest report, "COVID-19 and Human Rights. We are all in this together" [1], the United Nations advocates education as an ally for the defense of human 
rights-education is, after all, a fundamental element in the struggle against inequality and social vulnerability. Besides, the 2030 Agenda for Sustainable Development and its 17 objectives add a series of objectives to the area of EduCommunication. A veritable media ecosystem has made its way into modern society and, in order to navigate it as responsible citizens, students worldwide require certain critical thinking skills [2]. Accordingly, with teaching and learning processes in mind, it is vital to propose a new media curriculum to guide future educators towards the acquisition of updated media skills. For this reason, the goal of this chapter is to delve into the new AlfaMed Curriculum for the training of teachers in media education [3], which has been based on the famous Curriculum for teachers on media and information literacy published by the UNESCO in 2011 [4]. For this reason, in this chapter is proposed a comparative study between both curricula, from a perspective of the aforementioned changes and transformations that citizens have been experiencing in the past decade.

One of the main goals set by the UNESCO in 2011 was to ensure that people, teachers in particular, were critical with the media. Adopting a critical stance towards the media is even more necessary today, when the pandemic has increased our media consumption and use of social networks [5]. This objective has been echoed in the new AlfaMed curriculum, which has been designed by AlfaMed Network researchers from different countries in Europe and Latin America.

This work is structured from a media conceptualization competence and key elements from the media curriculum. It analyzes the modules that are collected in both curricula, establishing thus a constructive and updated comparison, which reflects digital literacy's changes, new realities, and needs from the past decade.

\section{Media competences in the past decade}

The past decade will be remembered for the start of one of the most sterling pandemics in recent history, as well as for the unprecedented technological revolution that has transformed the world. For example, cloud computing has become widespread, the internet has become ubiquitous, social networks such as Instagram or Pinterest were created, the iPad revolutionized the market, and in 2011, Snapchat and Twitch appeared, paving the way to a new understanding of entertainment. On a massive scale, online video games have become a favorite among young people, especially through the use of consoles such as the PlayStation 4 (PS4) (see Figure 1). Social networks, however, display an everchanging landscape-Instagram is still around and YouTube and TikTok are some of the most popular platforms [5].

Children's first contact with tablets is happening earlier and earlier, at the same time that adults have borne witness to the evolution of desktop computers into increasingly lightweight, powerful, and cheaper laptops. There are mobile phones that can act as full-fledged computer replacements and cloud storage being used instead of USB flash drives. Music streaming services in the shape of mobile apps have rendered specialized audio player devices obsolete. This is the context where people of all generations, younger and older alike, are living.

Technological progress cannot be stopped-it is embodied by the creation of new products, companies that are constantly renewing themselves, and by users who demand more and more immediacy and quality service.

A new debate has surged amidst this panorama, regarding how the educational systems of different countries are responding to the diverse contexts, needs, and demands of a digital society that has seen how technologies have revolutionized the educational system as whole. With the arrival of the COVID-19, teachers from 
The Revolutionary Media Education Decade: From the UNESCO to the ALFAMED Curriculum... DOI: http://dx.doi.org/10.5772/intechopen.97804

\section{A Decade in Tech}

Notable tech products \& online services launched in the past decade

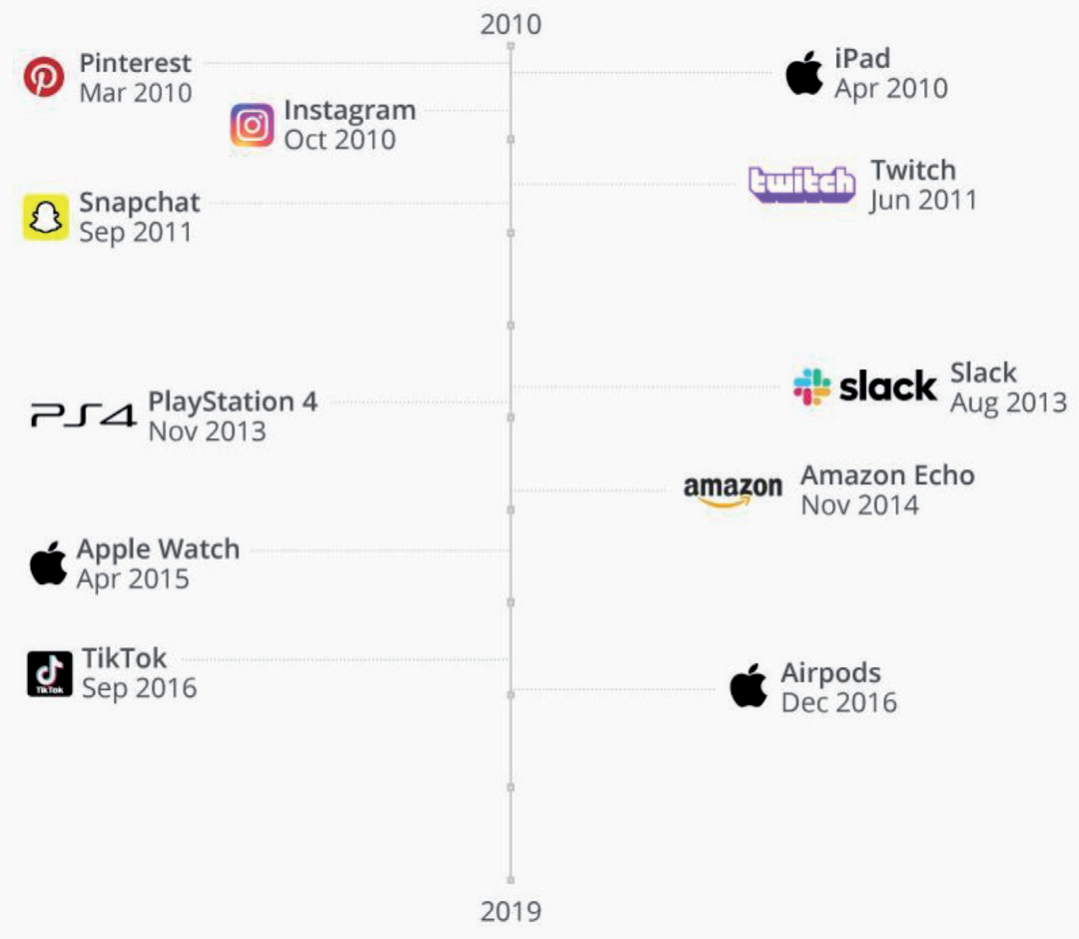

@

statista

Figure 1.

Evolution of the past ten years in technologies. Source: Statista, from: https://bit.ly/3lmHbGp.

all over the world had to adapt to new ways of learning and teaching, innovate with methodologies that could be applied online, reorganize spaces, resources, and time-in short, they had to devise a new way of understanding the curriculum.

Curriculum theories and definitions have been evolving for several decades, some stemming from objective-based planning models, typical of rationalist theories such as those promoted by Dewey, Tyler, or Bloom, while others emerged with the support of reconceptualist theories or processual or critical approaches. In one way or another, the term curriculum has been defined as a learning plan [6] and is constituted by capacities, values, contents, methods, and procedures that require certain management and evaluation models, which should be successfully conducted by educational organizations [7]. The term "curriculum" has been adopted in various ways, depending on the country, to respond to specific demands [8]. In this sense, and taking into account the current media society, the expression "digital competence" was coined to describe one of the essential skills that people should acquire [9], establishing, this way, a direct relationship between media competence and education - the teaching of this competence relies mainly on media and digital literacy processes.

In 2008, the European Parliament made an etymological approach of the concept of media education-a paramount concept that each country understood in its own way until the publication of the Media and Information Literacy Curriculum for Teachers in 2011 by the UNESCO [10]. Its aim was that people were able to identify the functions of the media and its devices in their daily lives, thus, empowering them to exercise their individual right to seek, receive, and transmit information and ideas from a critical thinking standpoint. 
Media education, media and information literacy (MIL) or media literacy (ML), were defined in the recommendation made by the European Commission to the European Parliament (August 20, 2009) on media literacy in the digital environment. Article 11 of this recommendation pleads for a more competitive audiovisual content industry and for a more inclusive knowledge society. It also stresses the importance of media access through a critical lens: to be able to understand and evaluate different means of communication with sound criteria. Moreover, article 18 of this recommendation emphasizes the need to address media literacy in different ways and at different levels, from educational systems to local authorities-they are closer to the population and should foster support initiatives of the non-formal education sector. Civil society, too, should actively contribute to the promotion of media literacy.

The truth is that being exposed to the media does not mean that you will acquire media competence-younger people, such as children and teenagers, lack criteria that would make them responsible and critical consumers [11]. This is why it is imperative that teachers learn skills and strategies that would allow them not only to consume media, but also to be active agents in the processes of construction of digitized meanings, becoming themselves, thus, intelligent prosumers who are then capable of transmitting the same skills to their students. Furthermore, teachers should become veritable designers who will take the initiative to, critically, creatively, and sustainably, access, select, produce, and distribute, digital material in any type of media [12]. Teachers have to work with centennials and millennials, which, in itself, pose new challenges regarding in-class dynamics. The implementation of new pedagogical methods and tools is directly related to teacher training and requires the development of multidisciplinary learning networks [13, 14].

For this reason, the curriculum must adapt to the aforementioned changes, to new ways of understanding communication processes, media consumption, and the building of citizenship identities. In a recent publication by Pérez-Tornero, Orozco and Hamburguer [15], "MILID Yearbook 2018/2019. Media and information literacy in critical times: Re-imagining learning and information environments," professionals from different fields, such as EduCommunication, have compiled reflections, research, and analyses on the current state of media and information literacy. This work is divided into three parts: MIL Augmenting Information Freedom and Knowledge Status, MIL and the Different Actors and Situations of Learning, MIL Providing New Opportunities. Specifically, and regarding media literacy teaching and learning processes, the importance of dialogue with students is mentioned as crucial in understanding the ideas, expectations, and assessments of other people in media environments.

\section{From the UNESCO's teaching curriculum to AlfaMed's: shared content, challenges and proposals}

There have been several changes in EduCommunication in the past ten years. However, the foundations laid by the UNESCO in 2011 on the media and information literacy curriculum for teachers have been maintained [4], although they have been updated by the AlfaMed Curriculum regarding media education training of teachers in 2021 [3]. Nevertheless, it's been observed, after a thorough analysis of the organization and the structure of both curricula, that the purposes, objectives, and curricular organizations have kept the same guidelines.

\subsection{The UNESCO and AlfaMed curricula shared content}

Both curricula share the fundamental goal of attempting to be a benchmark guide on the media education curriculum for teachers - they both agree that 
teachers need to be adequately trained so they will be able to critically and reflectively educate their students on media literacy.

Accordingly, the UNESCO curriculum proposed three topic areas for teacher training in thematic education: 1 . Awareness and understanding of the media and information for democratic discourses and social participation. 2. Evaluation of media texts and sources of information. 3. Production and use of media and information.

These topic areas are enriched by a curriculum that outlines seven competencies on which the teaching staff will be trained. It will establish a relationship between them with a series of central modules (9), electives (2), and three optional units that will enrich the teacher's curriculum. Likewise, all modules include units with their respective key topics, objectives, didactic approaches, activities, and evaluation recommendations.

The following are the seven competencies in which teachers will develop media literacy skills according to the UNESCO curriculum:

- Competence 1: Understanding the role of the media and information in democracy. "The MIL teacher will take the first steps in learning about the functions of the media and other information providers and about the importance they have for citizens and for educated decision-making."

- Competence 2: Understanding media content and its uses. "The MIL teacher must be able to demonstrate knowledge and understanding of the ways in which people use the media in their personal and public lives, the relationships between people and media content, as well as the use of the media for a variety of purposes."

- Competence 3: Effective and efficient information access. “The MIL Professor must have the ability to determine the type of information that is required for a particular task and retrieve it effectively and efficiently."

- Competence 4: Critical evaluation of information and information sources. "The MIL teacher will be able to critically evaluate a piece of information and its sources and incorporate the selected information into problem solving and analysis of ideas."

- Competence 5: Applying new and traditional formats to the media. "The MIL teacher will be able to understand the uses of digital technology, communication tools, and networks for the collection of information and decision-making."

- Competence 6: Positioning the sociocultural context of media content. "The AMI teacher will be able to demonstrate that knowledge and understanding of media content occurs within social and cultural contexts."

- Competence 7: Promote MIL among students and manage the required changes. "The MIL teacher will be able to use the knowledge and skills acquired through their AMI training to promote media and information literacy among students and will be able to deal with changes related to the school/college environment."

The AlfaMed curriculum maintains the same areas and competencies, although it makes a few changes related to modules and activities-it also updates the 
contents associated with social networks contexts, which had not emerged until 2011. Below is a comparative table of the modules proposed by the UNESCO and AlfaMed media literacy teaching curricula (Table 1).

In the case of the AlfaMed curriculum, a series of general modules have been proposed, without dividing them into basic or optional, in an attempt to respond to media literacy current needs. Likewise, while the UNESCO does establish a list of the competencies that teachers must acquire (see Figure 2), the AlfaMed curriculum does not establish such a relationship, instead, it considers the entire proposal as a general response to these competences.

Taking into consideration what has been described so far about the relationship between competences and modules proposed in both curricula, it is necessary to detail the didactic units corresponding to each module that constitute

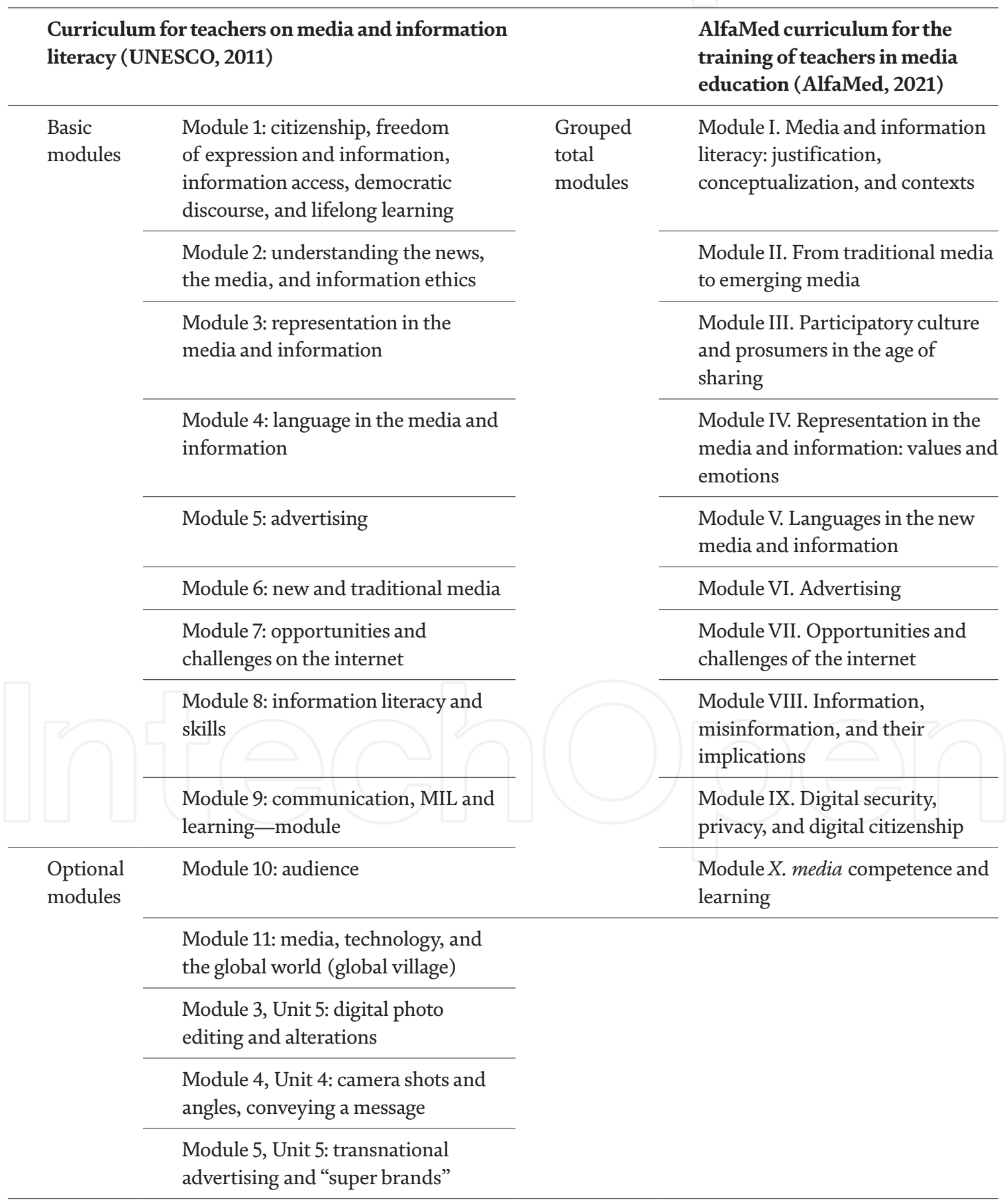

Table 1.

Comparative modules of the curricula for teacher training in media education UNESCO-AlfaMed. 
The Revolutionary Media Education Decade: From the UNESCO to the ALFAMED Curriculum... DOI: http://dx.doi.org/10.5772/intechopen.97804

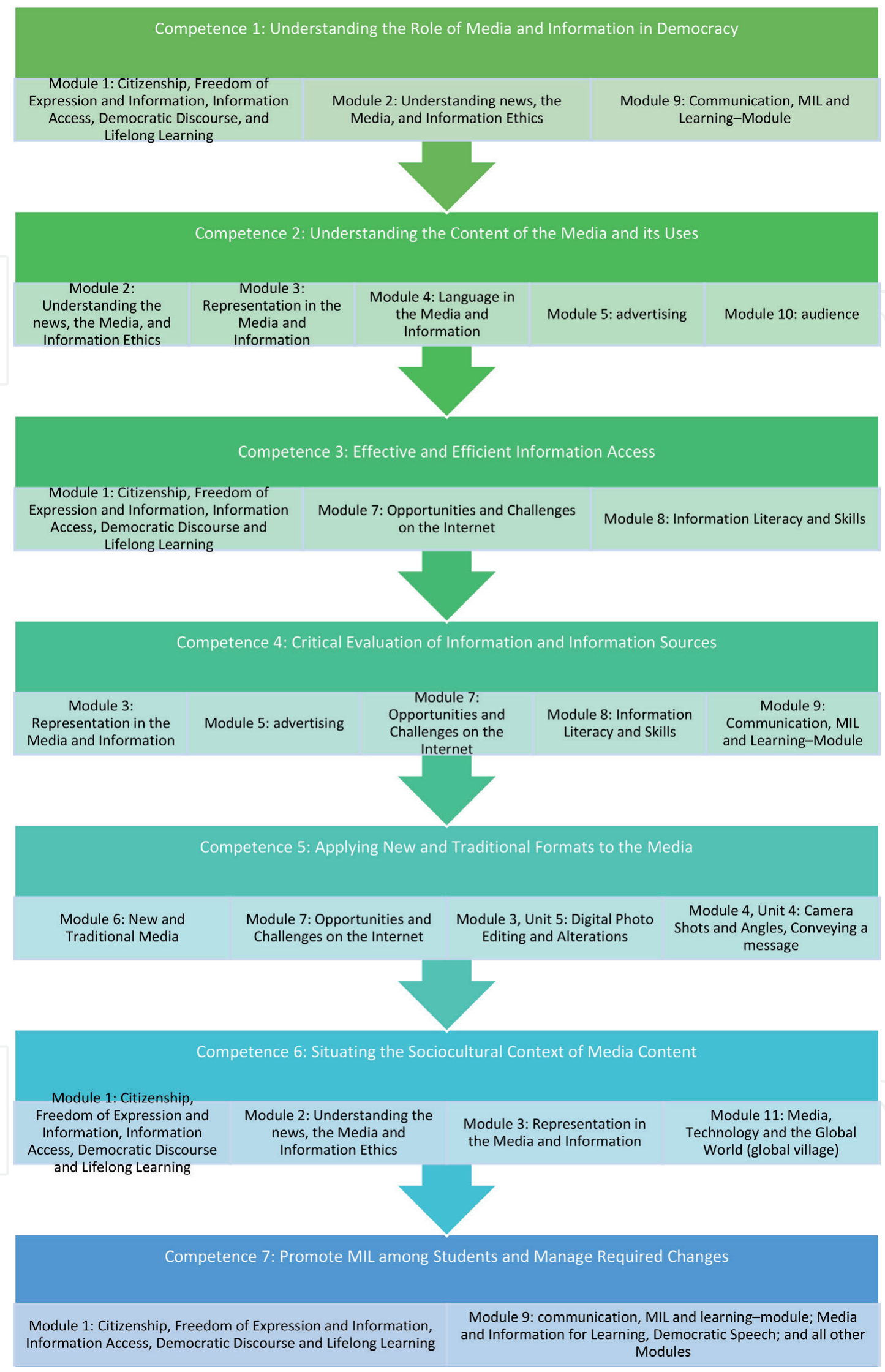

Figure 2.

List of competences and modules according to the UNESCO curriculum (2011).

the pedagogical and action-practical part of the teacher training in media and information literacy.

The comparison starts with the curriculum proposed by the UNESCO-we will analyze the relationship between its modules and units, from the basic and 
optional modules. Specifically, the first teaching units correspond to the following basic modules:

- Module 1: Citizenship, freedom of expression and information, information access, democratic discourse, and lifelong learning (from childhood to adulthood):

○ Unit 1: Understanding Media and Information Literacy: An Orientation

○ Unit 2: MIL and civic participation

- Unit 3: Interacting with the media and other information providers such as libraries, archives, and the internet

$\circ$ Unit 4: MIL, teaching and learning

- Module 2: Understanding the news, the media, and information ethics

$\circ$ Unit 1: Journalism and society

$\circ$ Unit 2: Freedom, ethics, and accountability

$\circ$ Unit 3: What generates news-exploring the criteria

○ Unit 4: The News Development Process: Beyond Five Whys and a How

- Module 3: Representation in the media and information

○ Unit 2: Industry Codes on Diversity and Representation

$\circ$ Unit 3: Television, movies, and book publishing

○ Unit 4: Performance and music videos

- Module 4: Language in the media and information

- Unit 1: Reading the media and information texts

$\circ$ Unit 2: The medium and the message: printed and broadcast news

$\circ$ Unit 3: Movie and story genres

- Module 5: Advertising

$\circ$ Unit 1: Advertising, revenue, and regulations

○ Unit 2: Public service announcements

○ Unit 3: Advertising: the creative process

$\circ$ Unit 4: Advertising and the political field 
The Revolutionary Media Education Decade: From the UNESCO to the ALFAMED Curriculum... DOI: http://dx.doi.org/10.5772/intechopen.97804

- Module 6: New and traditional media

○ Unit 1: From traditional media to new media technologies

○ Unit 2: Use of new media technologies in society—mass and digital communications

○ Unit 3: Uses of interactive multimedia tools, including digital games in classrooms

- Module 7: Opportunities and challenges on the internet

$\circ$ Unit 1: Young people in the virtual world

$\circ$ Unit 2: Challenges and risks in the virtual world

- Module 8: Information literacy and library skills

$\circ$ Unit 1: Concepts and application of information literacy

$\circ$ Unit 2: Information literacy and learning environment

$\circ$ Unit 3: Digital information literacy

- Module 9: Communication, MIL and learning—culminating module

$\circ$ Unit 1: Communication, teaching, and learning

$\circ$ Unit 2: Learning theories and MIL

○ Unit 3: Managing change to foster a favorable environment for MIL schools

Module 10 on Hearing is integrated into the optional modules that only contain one teaching unit under the same name, Module 11 on Media, technology and the global world (global village), which includes four units: Unit 1. Media ownership in today's global world; Unit 2. Sociocultural and political dimensions of globalized media; Unit 3. Information as a product (commodity); and Unit 4. The emergence of alternative media. The next module is the third one collected by the Unit 5. Digital photo editing and alterations; the fourth module deals with a didactic unit (Unit 4) on Camera planes and angles, transmitting a message and finally the fifth module that addresses transnational Advertising and "super brands," to end with a glossary of media and information literacy terms.

The second analysis corresponds to the AlfaMed curriculum, which integrates all the modules as fundamental elements of teacher training as follows:

- Module I. Media and information literacy: justification, conceptualization and contexts

$\circ$ Unit 1.1. Media and information literacy: justification and conceptualization

$\circ$ Unit 1.2. Media competence: dimensions and indicators

○ Unit 1.3. Contexts of intervention: formal, non-formal, and informal 
- Module II. From traditional media to emerging media

$\circ$ Unit 2.1. From mainstream media to digital and alternative formats

$\circ$ Unit 2.2. Digital and emerging media

○ Unidad 2.3. Social networks: new media for interaction

- Module III. Participatory culture and prosumers in the age of sharing

- Unit 3.1. Platforms for the consumption, production, and dissemination of content

$\circ$ Unit 3.2. The prosumer in a participatory society

$\circ$ Unit 3.3. Citizenship and participatory culture

- Module IV. Representation in the media and information: values and emotions

$\circ$ Unit 4.1. Ethics and responsibility in the representation of information: visual, textual, and multimodal aspects in different media types.

$\circ$ Unit 4.2. Gender, identity, and sexual orientation

$\circ$ Unit 4.3. Race, ethnicity, and identity

$\circ$ Unit 4.4. Inclusion and different capacities

- Module V. Languages in the new media and information

- Unit 5.1. General characteristics of digital codes and languages (algorithms, hashtags, emoticons)

$\circ$ Unit 5.2. Narrative strategies of the new media configurations

$\circ$ Unit 5.3. Genres of influence (booktubers, edutubers, science youtubers, gamers)

- Module VI. Advertising

$\circ$ Unit 6.1. The advertising message: from print to viral

$\circ$ Unit 6.2. New advertising formats, monetization, and datafication of human processes

$\circ$ Unit 6.3. Who creates / positions / configures the advertising message? From content curator to educational community manager

- Module VII. Opportunities and challenges of the internet

$\circ$ Unit 7.1. Uses and importance of the internet in society

$\circ$ Unit 7.2. Internet opportunities in the educational space as a means of informal learning and as an educational tool

$\circ$ Unit 7.3. Risks and problematic uses of the internet 
The Revolutionary Media Education Decade: From the UNESCO to the ALFAMED Curriculum... DOI: http://dx.doi.org/10.5772/intechopen.97804

- Module VIII. Information, misinformation and their implications

$\circ$ Unit 8.1. Opinions in the era of infoxication

$\circ$ Unit 8.2. Infodemic and types of misinformation (information disorders: virality, hoaxes, and fake news)

$\circ$ Unit 8.3. Contexts and networks: strategies to manage disinformation

- Module IX. Digital security, privacy, and digital citizenship

○ Unit 9.1. Approach to Big Data and information in the Cloud

$\circ$ Unit 9.2. Online privacy, security, and data protection

○ Unit 9.3 Malware, hacking, bots, and network fraud (phishing)

$\circ$ Unit 9.4. Digital citizenship, duties and responsibilities

- Module X. Media competence and learning

$\circ$ Unit 10.1. The role of the teacher as a guide and facilitator students' media competence development

- Unit 10.2. Participatory and innovative methodologies in the media context

- Unit 10.3. Educational resources and good pedagogical practices in media competence

As evidenced in the modules and didactic units, both curricula start from the same contextualizing thread of media education and develop its conceptualization, typology, and justification. Next, they move on to expand on the media education of teachers. The AlfaMed curriculum, however, progresses even further and updates the most relevant content related to today's hypermedia society-it offers topics such as social networks, fake news, risks, security and privacy, and ends with proposals and resources that will promote the development of media competence.

\subsection{Challenges and proposals for teacher training in media and information literacy}

These changes have driven the creation of different curricula in teacher training in media literacy and with them, new objectives emerge-teachers are being forced to adapt to new objectives, updated contents, and new teaching methodologies. More specifically, the AlfaMed curriculum proposes certain methodological strategies that will foster learning and teaching innovation. Flipped classroom is a good example of the latter. This methodology allows for certain learning processes to take place outside the classroom, which means that class time may be used for more personalized knowledge building. Mobile learning is another outstanding tool through which one may carry out educational practices regardless of location and time, making the most of the advantages of mobile devices. One of the most cutting-edge methodologies is design thinking-the teacher will suggest objectives and problems that should be handled by the students in a creative and efficient manner. Finally, in this new digital learning panorama, massive open online courses 
(MOOC) have turned into a crucial tool in online learning, since it allows students to better organize their time, at the same time that they foster responsibility, commitment, and autonomy.

Likewise, widespread social networks and the emergence of new actors in the digital landscape such as influencers-who have become role models for many young students-represent new challenges for teachers. These new forms of expression and communication, as well as the acquisition of information and content require specific skills on the part of teachers so they may safely deal with them in class. Consequently, both curricula, particularly AlfaMed's, make reference to and propose activities that will aid teachers when facing these challenges-an example of the latter is the use of edutubers in a school context.

Similarly, although the challenges can be rethought from the teaching point of view, without forgetting to emphasize the need for educational and political institutions to also support this development. Teacher training is part of the improvement of digital competences-school organizations, educations policies, and the publishing and technology industries must also get involved in the training and development process [16]. The updating of media teaching methods should continue to be promoted because, as stated in a study by Monteiro and Leite [17], students have highlighted the importance of implementing technologies in the class and have defended the need for an updated teacher training. It is essential to focus on the specialized training of teachers, detect their abilities and skills, and facilitate their respective processes of pedagogical and didactic adaptation.

\section{Conclusions}

As stated in this book chapter, one of the UNESCO's greatest challenges is to train teachers in the face of new realities and to enforce equity and quality in education. With regards to teaching needs in digital competences, the UNESCO has devised documents, such as the UNESCO/ILO Recommendation concerning the Status of Teachers (1966) or the UNESCO Recommendation concerning the Status of Higher Education Teaching Personnel (1997), which are updated every three years by an expert committee. Furthermore, taking into account the current media society, it also advocates for the implementation of media literacy programs that will address various elements such as production, representation, audience, and language-key aspects also defended by Buckingham [9]. The media training of the population, if conducted from a critical and responsible perspective and if carried out with the media, itself, in mind and using medium resources, will inevitably lead to reflections on how it may be updated and to how teacher training should be addressed within primary, secondary, and higher education $[18,19]$. Following this line, this chapter also defend the need to respect the new Digital Education Action Plan (2021-2027) proposed by the European Commission to promote high-quality digital education that is inclusive and accessible all over Europe-if there is something COVID-19 has taught us, it is that the use of technology in education grew dramatically and it has been vital to adapt all educational and training systems around it. This is an operation that should not stop. This plan includes two strategic priorities: the promotion of the development of a high-performance digital educational ecosystem and the improvement of digital skills and abilities to achieve true digital transformation. They both include the need to improve online infrastructure and connectivity, better planning for the development of digital skills under privacy and ethical standards, and the fostering of digital literacy at all ages. This represents an overhaul of the current program that will guide teachers to educate the citizens of the future. 
Therefore, it is necessary to continue to research and to prioritize the incorporation of tools, strategies, and training proposals on media education in the preparation of teachers, therefore, an update of the curriculum proposed by the UNESCO in 2011 is necessary, as is also advocated by Alcolea-Díaz et al. [4], in line with the AlfaMed curriculum for teacher training on media education published by the AlfaMed Network [3]. In addition, this need is also supported by a recent study from the Organization for Economic Cooperation and Development [20], which stated that less than $40 \%$ of educators consider themselves prepared to use modern technologies when teaching, and detailed significant differences between the countries of the European Union.

In conclusion, to promote the updating of the teacher's curriculum means to defend the quality of education. The adaptation to this training will respond to new demands and needs, and will benefit teachers, who will, in turn, educate their students as future citizens-participatory, critical, and responsible citizens in the current media ecosystem.

\section{Acknowledgements}

This work is framed under the development of the framework of Alfamed (Euro-American inter-university research network on media literacy for citizenship), with the support of the R+D Project: "Youtubers and Instagrammers: Media Competence in Emerging Prosumers" (RTI2018-093303-B- I00), financed by the State Research Agency of the Spanish Ministry of Science, Innovation and Universities and the European Regional Development Fund (ERDF). Also, some results are derived from the project: The construction of digital identity in older adults. Designing personalised learning trajectories in blended learning scenarios. Reference: PIC2-2020-18, from the University of Salamanca.

\section{Conflict of interest}

The authors declare no conflict of interest.

\section{Author details}

Paula Renés-Arellano ${ }^{1}$, Ignacio Aguaded ${ }^{2}$ and Maria Jose Hernández-Serrano ${ }^{3 *}$

1 University of Cantabria, Santander, Spain

2 University of Huelva, Huelva, Spain

3 University of Salamanca, Salamanca, Spain

*Address all correspondence to: mjhs@usal.es

\section{IntechOpen}

(C) 2021 The Author(s). Licensee IntechOpen. This chapter is distributed under the terms of the Creative Commons Attribution License (http://creativecommons.org/licenses/ by/3.0), which permits unrestricted use, distribution, and reproduction in any medium, provided the original work is properly cited. (cc) BY 


\section{References}

[1] United Nations (Ed.) (2020). COVID-19 and Human Rights. We are all in this together. https://bit. ly/2EsB1mR

[2] Sutiani, A., Situmorang, M., \& Silalahi, A. (2021). Implementation of an Inquiry Learning Model with Science Literacy to Improve Student Critical Thinking Skills. International Journal of Instruction, 14(2), 117-138.

[3] Aguaded, I., Jaramillo-Dent, D., \& Delgado-Ponce, A., (2021). Currículum AlfaMed de formación de profesores en educación mediática. MIL (Media and Information Literacy) en la era posCOVID-19. Octaedro.

[4] Alcolea-Díaz, G., Reig, R., \& Mancinas-Chávez, R. (2020). UNESCO's Media and Information Literacy curriculum for teachers from the perspective of Structural Considerations of Information. Comunicar, 62, 103-114. https://doi. org/10.3916/C62-2020-09

[5] Digital (2021). Global Overview Report. We are Social and Hootsuite. https://bit.ly/2OXVp4q

[6] Taba, H. (1974) Elaboración del Currículo. Buenos Aires, Troquel.

[7] Arroyo, J.A. (2009). Gestión directiva del currículum. Actualidades investigativas en Educación, 9(2), 1-17.

[8] Ramírez-García, A., RenésArellano, P., \& García-Ruiz, M. R. (2014). Presencia de la competencia mediática en los objetivos curriculares de la etapa de educación primaria. Teoría de la Educación, 26(1), 137-159. https://doi.org/10.14201/ teoredu2014261137159

[9] Buckingham, D. (2005). Educación en medios: Alfabetización, aprendizaje y cultura contemporánea. Paidós.
[10] Wilson, C., Grizzle, A., Tuazon, R., Akyempong, K., \& Cheung, C.K. (2011). Media and Information Literacy Curriculum for Teachers. UNESCO. http://hdl.handle.net/10722/141522

[11] Livingston, S. (Coord). (2011). Media literacy: ambitions, policies and measures. LSE. https://bit. ly/3rToi0e

[12] Hernández-Serrano, M., RenésArellano, P., Graham, G., \&amp; Greenhill, A. (2017). From prosumer to prodesigner: Participatory news consumption. [Del prosumidor al prodiseñador: El consumo participativo de noticias]. Comunicar, 50, 77-88. https://doi.org/10.3916/C50-2017-07

[13] Zayas, C., \& Ávila-López, L.A. (2018). Desafíos de los docentes frente a la Generación Millenial y Centennial. In C. Zayas, \& L.A. Ávila-López (Coords.), Cuarta Revolución Industrial: Tecnologías en las áreas administrativas, contables, informáticas y de negocios.

(pp.19-31). Pearson.

[14] Schwieger, D., \& Ladwig, C. (2018). Reaching and Retaining the Next Generation: Adapting to the Expectations of Gen Z in the Classroom. Information Systems Education Journal, 16(3), 45-54. http://isedj.org/2018-16/ ISSN: 1545-679X

[15] Pérez-Tornero, J.M., Orozco, G., \& Hamburguer, E. (2020). MILID Yearbook 2018/2019. Media and information literacy in critical times: Re-imagining learning and information environments. UNESCO, UAB. https:// bit.ly/3rMife1

[16] Sánchez-Cruzado, C., SantiagoCampión, R., \& Sánchez-Compaña, M.T. (2021). Teacher digital literacy: The indisputable challenge after COVID-19. Sustainability, 13, 1858, 1-29. https://doi. org/10.3390/ su13041858 
The Revolutionary Media Education Decade: From the UNESCO to the ALFAMED Curriculum... DOI: http://dx.doi.org/10.5772/intechopen.97804

[17] Monteiro, A.R., \& Leite, C. (2021). Digital literacies in higher education: skills, uses, opportunities and obstacles to digital transformation. RED, 21(65). https://doi.org/10.6018/red.438721

[18] Ferrés, J., \& Masanet, M.J. (2015).

La educación mediática en la universidad española. Gedisa.

[19] Tiede, J., Grafe, S., \& Hobbs, R. (2015). Pedagogical media competencies of preservice teachers in Germany and the United States: A comparative analysis of theory and practice. Peabody Journal of Education, 90(4), 533-545. https://doi.org/10.1080/01619 56X.2015.1068083

[20] OECD (2019). TALIS 2018 Results (Volume I): Teachers and School Leaders as Lifelong Learners, TALIS, OECD Publishing. https://doi. org/10.1787/1d0bc92a-en 